\title{
THE IMPORTANCE OF SOCIO-ECONOMIC BACKGROUND ON EDUCATION IN AN UNEQUAL SOCIETY: THE CASE OF ISRAEL
}

\author{
Shirly Cohen, Valér Veres
}

\begin{abstract}
Intergenerational mobility in salary describes the correlation between the parents' economic background and their children's success in labor market and it is very important to understand the long term meanings of inequality. It was found that there is an intergenerational reproduction regarding social classes: basic economic and educational inferiority is maintained and even expanded throughout life (Brandes, 1996). The literature in Israel mainly focuses in the subject of children's academic success regarding the question of the social-economic status influence on parenting of adolescents. The research findings show that there is a direct correlation between the parents' education level and their children's education level, and there is a direct correlation between parents' economic status and their children's education (Brandt, 2018). The international research findings (amongst the OECD countries) shows a disturbing picture regarding the education system in Israel and the intergenerational mobility status. Israel is ranked in all PISA international test cycles in the three first places of students' gaps, and at the same time, the poverty rate stays stable along the years and ranked high in international observations. In this article the author will present the theories explaining the individual's social status and the cause of intergenerational fixation. In addition, the author will present the education system's importance in social mobility and the reasons influencing the student's success in school. This paper goal is to emphasize the important aspects in the research literature, which might improve the education system in Israel and reduce students' gaps in schools and therefore support breakthrough to real equality in the Israeli society.
\end{abstract}

Keywords: Intergenerational mobility, salary, inequality, education systems, poverty, status, cultural capital, academic achievements, PISA test.

\section{Introduction}

Equal opportunities is an ideal that perceived by many people as a compass that should direct public policy, since many people prefer that the person's welfare level will be set more by his own choices and efforts rather than a byproduct of his birth circumstances. While it is hard to measure the opportunities each individual has; the economical and sociological literature refers to intergenerational mobility, i.e. correlation between the parents' economic and social status and their children status when becoming adults - as estimation to the equal opportunities level in a specific society (Chief Economist Division of Israel, 2017). A social status intergenerational reproduction was found: basic economic and academic inferiority is kept and even widen during life and it seems that the weak groups in society have difficulties to realize the open opportunities they have (Brandes, 1996).

In this respect, the article will present various theories explaining why a social class fixation exists and what is the education system's role in social mobility. This article aims to identify the main problems in the current education system in Israeli society, based on empirical data, and with a desire to lead to equal opportunities that every student in the system deserves. 


\section{How is society status determined?}

The purpose of the present study was to investigate senior secondary school students' preference for numerical information in relation to numeracy and achievement in mathematics in Nigeria.

The individual's social status is determined based on his education, income and occupation (Brandt, 2018). Davis and Moore (1949), claimed that there are differences between social roles in society. The nature of these roles is distinguished by the importance of theirs contribution to society and to the achievement of its goals.

There are roles in society which are aimed to achieve society's main goals and values that may be manned only by qualified people who have rare skills (some are congenital and some can only be purchased through special education and training), and there are less important roles which manning does not require such special skills. The various roles are also expressed in differential division of rewards (as income), while the rewarding scale is compatible with the role's importance level. (see Yasur et. al., 2003). As a result, society legitimizes inequality in controlling the resources that create various ranking of people that determine their relations and explains the existence of social classes (Shapiro and Ben Eliezer, 1989). Therefore, the individual's starting point in society is his economic ability, his education level and personal skills - frequently causes huge gaps in his personal standard of living and his social status as a civilian (Brandes, 1996).

There is an interesting question among many researchers regarding the influence of social status on raising children. A research performed by the Israeli Ministry of Finance in 2012 by Galit Ben Naim, senior manager in the state income administration and Alexei Belinsky, economist in this department, found that $80 \%$ of Israelis who were born to poor parents - will stay poor and about $90 \%$ of children born to rich parents - will be rich. The research was based on salary data of about one million Israelis in the years of 2003-2009. This research was announced as the biggest research in Israel in the subject of social mobility (Ministry of Finance, 2012).

Therefore, the following question arises: what are the factors explaining intergenerational fixation and how can the education system be a major engine that reproduces it?

Bourdieu (1984) suggests an explanation to the intergenerational fixation by presenting the cultural capital dimension as a factor of social arena of competition between its life styles and the hierarchy of evaluated and legitimate cultural contents compared to excluded and lowered contents. Cultural capital: refers to the power based on the content and knowledge that determine social superiority and allegedly belonged to social classes that enjoy legitimacy and even dominance and benefits in all or part of the social structure. Unlike the economic capital, most of the cultural capital is not directly transferable to others (inherited) and transferring it from generation to generation involves a renewed acquisition of knowledge, proficiency and skills. The main components of cultural capital that allow social superiority are objects, products and works, education, knowledge and the taste related to the respected culture and arts, namely to contents that were commonly agreed as the leading values of the modern world. Such taste preferences tend toward classical artistic music, painting traditions, literature, poetry, the drama of modern Western civilization, knowledge and proficiency of history, science and geography.

Bourdieu (1984) explains that cultural capital significantly influences grades gaps between students. He claims that schools reward students by their cultural capital that defined as "a tool for socially symbolic wealth transfer". Socially, this arena is not static and is characterized by struggles between forces that preserve, protect and reproduce the existing situation, and the forces who try to change it. This is a 
struggle on the nature and location of cultural content and certain life patterns in it. This approach considers cultural action and all actions related to aesthetic judgment and taste preferences as a tool for creating and maintaining cultural uniqueness and social distinction between groups, sectors and communities (see Regev, 2011).

The difference between consumption modes of those who have higher cultural capital and those who have low cultural capital is in the distinguished between a pure look or taste and a naive look or taste, a distinction that characterizes modernity in general and modernism in art in particular. Pure taste is about the fundamentally aesthetic rational decoding ability that involves theoretic knowledge and information about the works, emotional restrains and disconnection of the aesthetic experience from other activities. There are traits rooted in a social framework, and deep believes that traits are universal and natural. This enable using them as a tool for inequality reproduction and preservation, since this belief allows to view the naive taste as a kind of disability that prevents disabled from separating the aesthetic experience from other activities and thus, reaching deep insights and pure aesthetic joy. The cultural capital's power is inherent in traits sets that are acquired and internalized at a very early age making it very difficult for individuals to abandon the lifestyle they were raised in, and especially to acquire through theirs life the opportunity to join a prestigious lifestyle, and classes that enjoy social advantages.

Observing the individual and his available options to real social mobility - i.e., from one lifestyle to another, from one status group to another - shows that the cultural capital distribution and the habitus patterns in social space do not allow much flexibility. According to Bourdieu, a very important cultural social transformation is occurring in the education system: it causes individuals to perceive structural class differences as interpersonal differences that consciously related to the individual's innate or natural abilities. Therefore, the cultural capital is component that its acquisition and accumulation depend on the person's initial social position. At the same time, it is embodied and perceived as the individual level, abilities and personal traits. Consequently, the chances of success are higher for children entering the education system equipped with initial components of this capital that they have acquired in theirs home societies (from parents who already have higher cultural capital), than children who come from homes without cultural capital. Children who grow up with parents who has poor or no cultural capital have much more difficulties to meet the success requirements set by the education system, even though the educational system demands are usually perceived as a result of personal abilities as diligence, perseverance, investment and even intelligence (Regev, 2011).

By the end of the 1950's Bendix and Lipset performed a comparative research between different industrial societies and found that in fact there are no big differences in the mobility rates between countries as the United States, Sweden, France, West Germany and Japan. Their conclusion was, that the United States (that is perceived as an equal opportunity states) are not different from the other industrial countries and that the mobility rates are similar and defined by needs and demands of modern industrial instructor (Bendix, 1959).

Eight years later, Blau and Duncan (1967) examined the intergenerational mobility rates in the American society, i.e. the children mobility in relations to their parents. They ranked the occupational structure on a seven categories scale, at its top there are managers and professionals and, on the bottom, the unqualified workers. The researchers found that the essential variables for understanding a person's mobility in society depends on: a) the father's level of education; b) the father's profession; c) the son's level of education; d) the nature of the son's first profession. A causal correlation between the following variables was found: the son's education is the most influencing factor on his first profession and on his profession in general. The father's profession has indirect influence on the son's profession since the 
father's profession influences indirectly the way he educates his son. In 1985 Erikson and Goldthorpe (2002), performed an additional research that examined again the social mobility rates in the United States and the findings showed again similar results, and in many researches performed around the world have also found this positive correlation (Dimaggio, 1982; Shapiro and Ben Eliezer, 1988).

The economic status is an additional factor component that influences social mobility in the education context: education serves as a social selection tool while its legitimacy is not harmed. Many researches show that low classes children have difficulty adjusting to the educational system and use it as a leverage of social mobility. However, achievement, even if they get better at school, are inevitably influenced by class affiliation factors. A competition between poor and rich children are not under equal terms.

A rich child has the benefits and opportunity to use private teachers, he has a separate room with his own desk and he can attend a private school. Unlike him, a low-class child lives in conditions of density family instability and even his linguistic development is poor. In addition, it seems that the lower-class children do not develop the aspiration to academic success. Many of the lower class who aspired to succeed in schools failed. Many sociologists and anthropologists often attribute this aspect to the poverty culture that runs in lower classes from generation to generation. This culture encourages passivity and acceptance of fate, cynical relations to the environment, reluctance to get organized, abandonment and neglect. The correlation between social class and lifestyle is prominent in all social classes, but the middle and high classes translate their money to consumption patterns that encourage academic achievements and bring the child closer to school: parents tend to be much more involved in the child's education, interest in his achievements and encourage him if he fails. However, in low class the parents do not show any interest in the child's situation, and often there is hostility towards school and its teachers, moreover and it mainly prevent the child from proper entrance to work circle (Shapiro and Ben Eliezer, 1988). Therefore, gaps and classes are formed in society until grouping of identical social classes that are expressed in the economic structure created by economic reality, which create culture and intergenerational reproduced pattern.

The prevalent assumption in this paper is that living conditions, opportunities and educational and cultural backgrounds are factors that influence the values, attitudes, and expectations when it comes to children. The research question is, how these factors changed over time in Israel and how the school achievements of the children changed?

\section{Research Questions:}

1. What are the Israeli children achievements compared to other OECD countries?

2. Do social-economics factors influence school achievements in Israel?

\section{Data analysis and discussion: social background and educational achievement}

This article is based on empirical data collected by Israeli National Insurance Institute on 2017 aimed to determine "Poverty Line"- Dimensions of Poverty and Social Gaps (Annual Report 2017 State of Israel).

The poverty report in Israel includes several databases:

a) Social Security allowance data (such as: work grant, old age allowance, survivor's allowance, income supplement etc...). 
b) Data regarding the income reported to the tax authority.

c) Employment / Unemployment Rate.

d) Economy wages.

e) Family size.

f) Gini Index - which examines the disposable income over time and determines the income distribution inequality.

There are significant correlations between education, employment and income: in Israeli society, therefore, one of the main sociological questions in social stratification is the meaning of these correlations. Due to the employment structure in modern society, which sometimes is called "experts' society", education is perceived as the most important mean of social mobility, while the expertise level required for many professions is increased every year. The individual's starting point is provided by school in achieving the expectations of the society and the employment system and uses a categorizing mechanism to allocating people in society. Although school has to be open to all and provide full equal opportunities, it seems that significant gaps already exist when a child enters school and it eventually reflects on his future success (Chief Economist Division, 2017). In Israel, school is perceived, all along, as the main instrument given to society aimed to overcome the disparities between the members of society, gaps originate in origin, emigration time and class differences. School was supposed to develop equally its student's skills, especially when the students come from problematic background of another language, different culture, poverty, and families in crisis. Especially in these cases, we expect school to be the place in which the child's background data will be corrected and he will be given the opportunity to develop and be like all other students. But, in fact, the education system developed in Israel became the factor determining class differences in Israeli society (Aviv, 1990). Although the last sentence claimed on 1990 and we are almost 30 years later, while checking the findings along the years will show that this sentence is still relevant today. The Israeli National Insurance Institute's Annual Report 2017, presented very worrying findings regarding the poverty extent and the gaps in the Israeli society. According to this report, about 446,400 families were defined as poor (in this year), including $1,780,500$ people of which 814,800 children (see table 1) and we may also find similar findings in the last 20 years presented in figure 1 .

Table 1: Poverty incidence (percent) and number of poor, 2007-2016

\begin{tabular}{|l|l|l|l|}
\hline & $\begin{array}{l}\text { Before transfer } \\
\text { payments and direct } \\
\text { taxes }\end{array}$ & $\begin{array}{l}\text { After transfer } \\
\text { payments and direct } \\
\text { taxes } \\
\text { poverty } \\
\text { reduction } \\
\text { After transfer } \\
\text { payments and } \\
\text { direct taxes }\end{array}$ \\
\hline 2017 & $28.4 \%$ & $18.4 \%$ & $35.4 \%$ \\
\hline Families & $28.4 \%$ & \\
\hline
\end{tabular}




\begin{tabular}{|c|c|c|c|}
\hline Persons & $28.0 \%$ & $21.2 \%$ & $24.3 \%$ \\
\hline Children & $33.5 \%$ & $29.6 \%$ & $11.8 \%$ \\
\hline \multicolumn{4}{|l|}{2016} \\
\hline Families & $28.8 \%$ & $18.5 \%$ & $35.8 \%$ \\
\hline Persons & $28.9 \%$ & $21.9 \%$ & $24.2 \%$ \\
\hline \multirow[t]{2}{*}{ Children } & $34.9 \%$ & $31.0 \%$ & $11.2 \%$ \\
\hline & $\begin{array}{l}\text { Before transfer } \\
\text { payments and direct } \\
\text { taxes }\end{array}$ & $\begin{array}{l}\text { After transfer } \\
\text { payments and direct } \\
\text { taxes }\end{array}$ & $\begin{array}{l}\text { Rate of } \\
\text { poverty } \\
\text { reduction } \\
\text { After transfer } \\
\text { payments and } \\
\text { direct taxes }\end{array}$ \\
\hline \multicolumn{4}{|l|}{2017} \\
\hline Families & 722,100 & 466,400 & 255,700 \\
\hline Persons & $2,352,900$ & $1,780,500$ & 572,400 \\
\hline Children & 928,800 & 814,800 & 109,000 \\
\hline \multicolumn{4}{|l|}{2016} \\
\hline Families & 719,700 & 462,100 & 257,600 \\
\hline Persons & $2,377,600$ & $1,802,800$ & 574,800 \\
\hline Children & 944,100 & 838,500 & 105,600 \\
\hline
\end{tabular}

(Source: National Insurance Institute - Director of Research and Planning (2018), Annual Report 2017: Dimensions of Poverty and Social Gaps, State of Israel, p.12) 
Figure 1: Poverty Incidence of families, persons, children and the elderly, 1998-2017

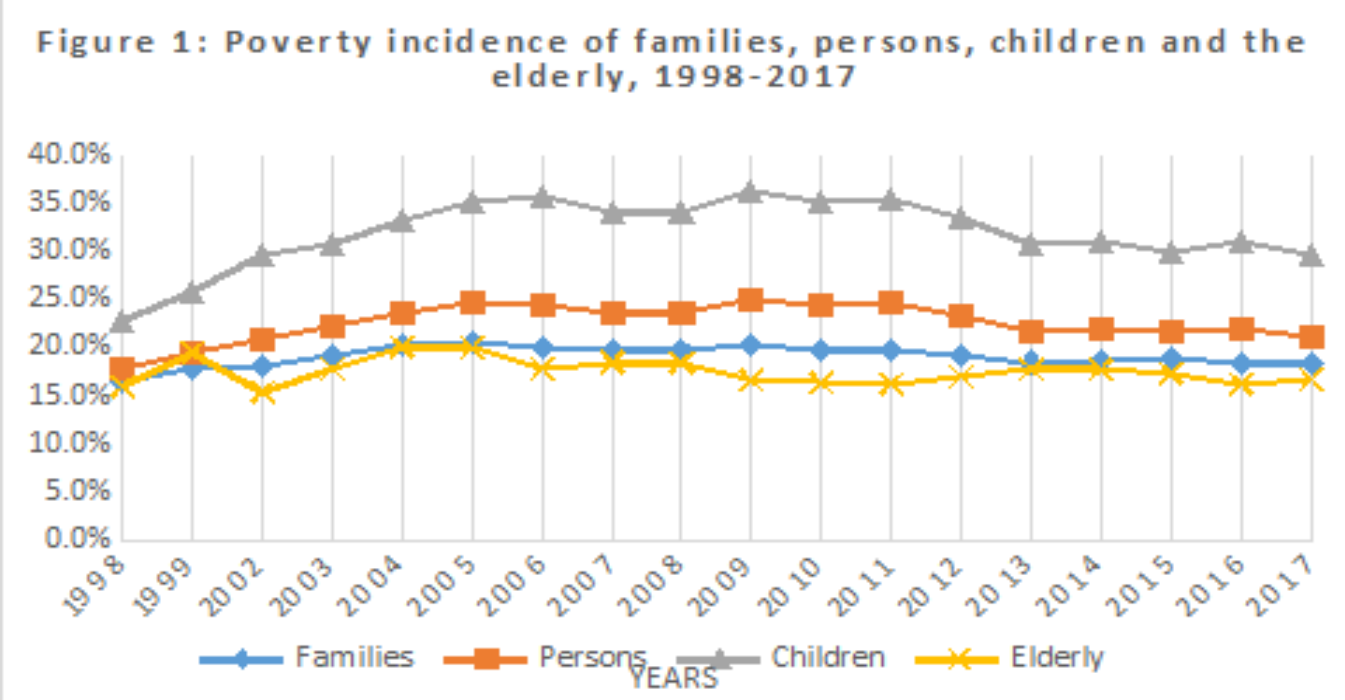

(From: National Insurance Institute - Director of Research and Planning (2018), Annual Report 2017: Dimensions of Poverty and Social Gaps, State of Israel, p.11.)

In international view, the poverty extent in Israel calculated by the OECD in a similar method developed by the National Insurance Institute with some differences, was found that in 2017 about $38 \%$ of Israeli population is poor (low class) or in danger of poverty (middle-low class) and about $23.2 \%$ of Israeli children are absolutely poor. It means that, according to this index, each fourth child (and each third child according to the National Insurance Institute index) is defined poor child. Due to these findings, Israel is placed in the top of the developed countries in poverty rate among people and in second place in children's poverty rate (see figure $2 \&$ figure 3 ).

Figure 2: Poverty incidence among children by disposable income

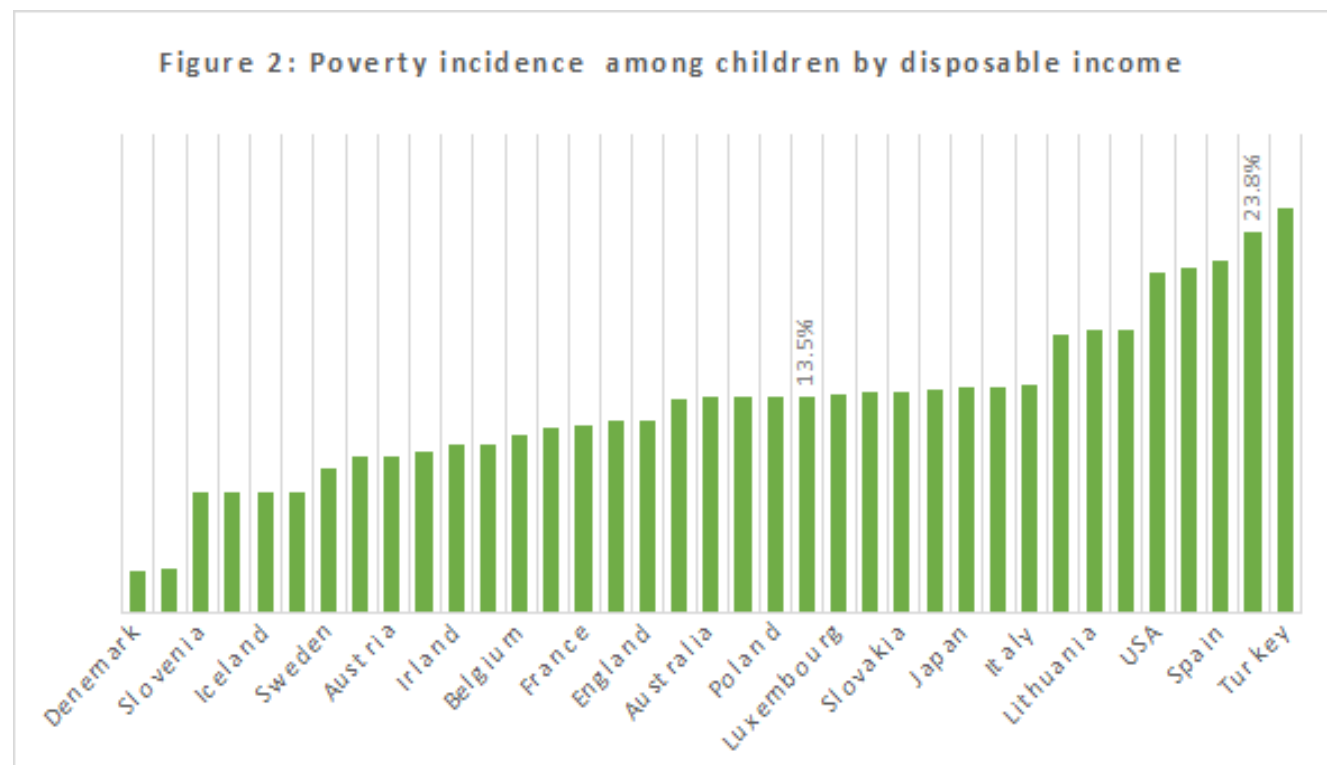

(From: National Insurance Institute - Director of Research and Planning (2018), Annual Report 2017: Dimensions of Poverty and Social Gaps, State of Israel, p. 43) 
Figure 3: Classes distribution in Israel by the OECD definition in 2017

Figure 3: Classes distribution in Israel by the OECD definition in 2017

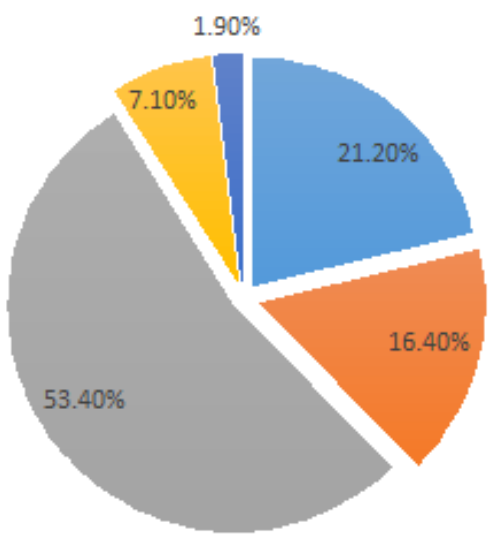

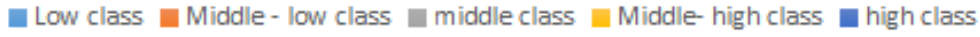

(From: National Insurance Institute - Director of Research and Planning (2018), Annual Report 2017: Dimensions of Poverty and Social Gaps, State of Israel, p.32)

These findings show that the Israeli international status in education is also compatible with the findings of social class fixation. Israel is prominent in the largest grade scattering among all countries participated in the research over the years. In all examined areas and all research cycles, Israel ranked in one of the first three places in grade scattering index over the years 2006-2015 (PISA report 2015-2016). Those finding's mean that the education system in Israel characterized in a very large variance in students' achievements. Reviewing the PISA tests in figure no. 4 shows the rate of excelled and the rate of having difficulties in the years 2006-2015 in each of the domains and in all domains together. The main goal of PISA research is to evaluate the level in which 15 years old students are able to use knowledge and skills they have acquired along their way in the education system in their country in order to cope with challenges they will face in their adult lives (after graduating their obligatory studies). The PISA initiators selected the age of 15 because it considered as the age that the obligatory education ends in most of OECD countries (PISA report, 2015). In this manner each country has the opportunity to examine the productivity of its education system and evaluate the students' achievements in common and agreed international point of view (RAMA, 2016). ${ }^{1}$

The research report findings indicate a very high rate of students with difficulties (described in Figure 4) - almost one third of the students in Israel have difficulties in at least one of the literacy domains and about a fifth of the students have difficulties in all three domains. Moreover, the rate of excelled students is very close to the OECD average rate, on examining each domain separately and when examining all three domains together. The variance sources in students' achievements in Israel are diverse and complex, but the most prominent gaps are the gap between Hebrew speakers and Arabic speakers, which is about 100 points and expanding, and the gaps between students of different social-economic-cultural background, which is about 90 points between students from high background and students from low background.

${ }^{1}$ National Authority for Measurement and Evaluation in Education (RAMA) 
Figure 4: the rate of excelled and having difficulties along the years (Israel, OECD average, Hebrew speakers and Arabic speakers)

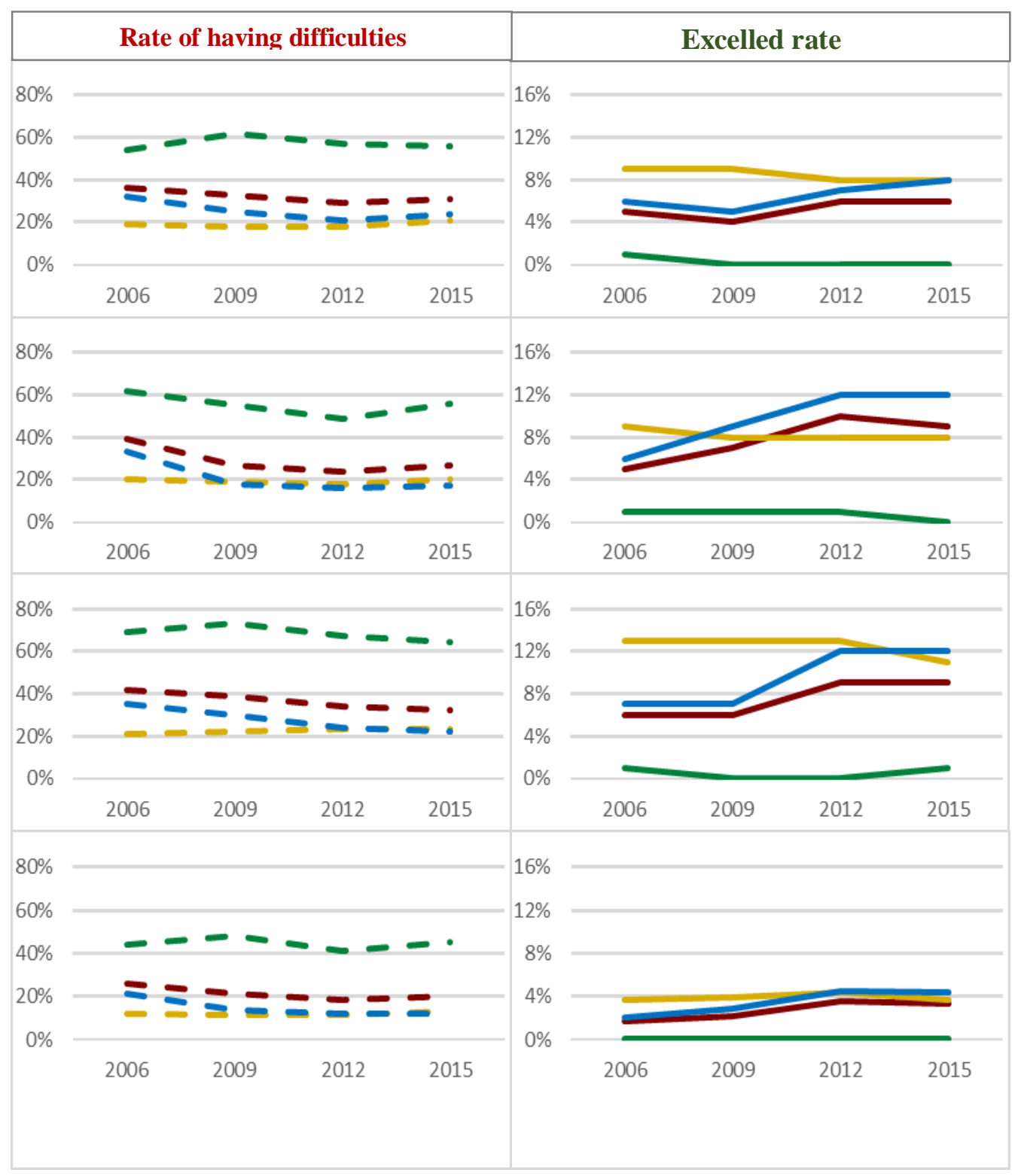

(From: RAMA (2016) "PISA 2015": literacy among 15 years old students in sciences, reading and mathematics", the ministry of education, p.129)

Based on data presented by RAMA (PISA 2015 Test), there is a correlation between students' socialeconomic-cultural (SEC) background and their achievements: as higher the students' SEC background, the higher are their achievements. In 2015 the achievements gaps between students from high background and students from low background was 91 points in sciences, 89 points in reading and 87 points in mathematics. The gaps have remained virtually unchanged over the years. Among Hebrew speakers the achievements gaps between students from high background and students from low background are similar to the gaps in the general population - 94 points in sciences, 87 points in reading and 84 points in mathematics. Among Arabic speakers the gaps are smaller comparing to the general population - 31 points in sciences, 22 points in reading and 32 points in mathematics. Researches that do not engage with literacy but examine proficiency in the curriculum material, the gap between the sectors greatly reduced when considering the students' social-economic-cultural background. In all literacy domains the excelled rate is larger as the students' social-economic-cultural background is 
higher. Among students of high, middle and low SEC background the excelled rates are: in mathematics $2 \%, 9 \%$ and $16 \%$, in reading $2 \%, 9 \%$ and $17 \%$, in sciences $1 \%, 5 \%$ and $12 \%$ respectively. Students of high, middle and low SEC background who have difficulties are: in mathematics 18\%, 28\% and 47\%, in reading $49 \%, 28 \%$ and $19 \%$ and in sciences $40 \%, 23 \%$, and $16 \%$ respectively (RAMA, 2016).

\section{Conclusions}

In 2014, the state of Israel was at the first place in education gaps. The question is: how do these gaps express?

The gap of investing in education between a student who lives in Savion, which is a city categorized as high cluster by the Central Bureau of Statistics, and a student who lives in Rahat, which is a village categorized as the low cluster, may be up to 16 times. Meaning, a student who were born in Rahat and a student who were born in Savion will receive very totally different investment from the state and from the public institutions in education, therefore, one can understand what the implications on their life chances are. An additional issue is the eligibility to matriculation: the national average is $49.8 \%$, while high class cities the average is closer to $70 \%$, the average in development towns is closer to $50.1 \%$, the average in Arab settlements is $38 \%$ and the average in Bedouin settlements is only $28.2 \%$. So what does this mean? That every child who was born in Savion or Ramat Hasharon (high class cities) is a smarter child? And based on additional data, there is a tight linear correlation between children's socio-economic background and their academic achievements. I.e., the lower the child's socio-economic background, the lower his academic achievements and vice versa: the higher the child's socioeconomic background the higher his academic achievements. So, what does this testify regarding our education system? What is the fundamental role of it? Can it really direct the individual to social mobility?

According to the latest results of PISA test research of 2018, the Israeli students' achievements are lower than ever. There are significant gaps between students based on economic background and there are extensive gaps stemming from sectorial background. Unfortunately, Israel is placed still in the first place considering gaps between the strong students and the weak students in all 78 countries tested in all three subjects, and this means that the students in Israel are not ready for adult life and labor market (Shahar, 2019).

This article's goal is to reflect the Israeli PISA data over the years in relation to social mobility. The author hopes that this paper will serve as "wake up call" to the relevant authorities (the Ministry of education and the Ministry of finance) that will result in necessary re-definition of its mission, policies and resources of Ministry of Education and the local authorities in charge of budget allocation.

\section{Bibliography}

Avinoam, N. (2015): Conference video: Gaps in Public Education. Taub Center. https://www.youtube.com/watch?v=6d051dzkyQQ

Aviv, A. (1990): Israeli Society: Society in Formation Process. Ra'anana: Israel. The Ministry of Defense.

Ben Naim G. and Belinsky A. (2009): Salary widening in Israel - Analysis of salary mobility in economy over the past decade. Ministry of Finance, State of Israel. 
Bendix, R. and Lipset, S. (1966): Class, Status and Power: Social Stratification in Comparative Perspective. NY: The Free Press; 2nd edition

Bendix, Reinhard and Berger Bennett. (1959): Images of Society and Problems of Concept Formation in Sociology. Pp. 92-118 in Symposium on Sociological Theory. Edited by Llewelyn Gross. New York: Harper and Row.

Blau, P. and Duncan O.D. (1967): The American Occupational Structure. New York: The Free Press.

Bourdieu, P. (1984): Distinction: A Social Critique of the Judgment of Taste. Harvard University Press.

Brandes, A. (1996): The Third Leap - Changes and Reforms in the Education System in the 1990s. Publications Department, Ministry of Education.

Brandt, I. (2018): The impact on parenting and predicting child and adolescent achievement, psychoactuality. The Psychological Association Quarterly in Israel. Pages 47-52.

Chief Economist Division (2017): Intergenerational Mobility in Israel Salary, Ministry of Finance.

Davis, K., and Moore W.E. (1949): Toward a Theory of Stratification, American Sociological Review 10:242-249.

DiMaggio, P. (1982): Cultural Capital and School Success. American Sociological Review 47 (April, 1982).

Goldthorpe., H. and Erikson, R. (2002): Intergenerational Inequality. A Sociological Perspective. Economic Perspectives, Volume 16, Number 3 Summer 2002, Pages 31-44.

National Insurance Institute - Director of Research and Planning (2018), Annual Report 2017: Dimensions of Poverty and Social Gaps, State of Israel.

RAMA (2010). "PISA 2009": literacy among 15 years old students in sciences, reading and mathematics", The Ministry of Education.

RAMA (2013): "PISA 2012 Israeli view", The Ministry of Education.

RAMA (2016): "PISA 2015": literacy among 15 years old students in sciences, reading and mathematics", The Ministry Of Education.

RAMA (2016): Status: Mathematics Studies in Israel - Trends and Findings from the Education System in Israel, Report $1+2$, Ministry of Education.

Regev, M. (2011): Sociology of Culture: General Introduction. Ra'anana: The Open University.

Shahar, A. (2019): PISA Tests 2018: Student grades in Israel are lower than OECD average, Calcalist website.

Shapiro, Jonathan and Ben-Eliezer, Uri. (1989): Fundamentals of Sociology. Tel Aviv: Am Oved.

Yasur, A., Oved, Y., Rosolio, D., \& Rosner, M. (2003): Social justice and equality in a changing world. Raanana: Ha'Kibbutz Ha'Meuhad

\section{Authors}

Shirly Cohen, doctoral researcher, Babes-Bolyai University, Department of Sociology, Cluj-Napoca (Romania). Email: shirlyc570@gmail.com 
Valér Veres supervisor, Babes-Bolyai University, Department of Sociology, Cluj-Napoca (Romania). Email: veres.valer@ubbcluj.ro 